La tercera de estas selecciones es la más limitada en el número de páginas y la más modesta en su presentación. Así como la dirigida por Pedro Henríquez Ureña parece destinada al público lector, la de Raimundo Lida, en cambio, se hizo principalmente para uso de estudiantes universitarios y de enseñanza superior. Por otra parte, esta colección de la Editorial Araujo está específicamente consagrada a los niños de las escuelas públicas de la nación. De ahí que el material que la integra esté seleccionado casi exclusivamente de $L a$ Edad de Oro, la revista para niños que Martí fundó, dirigió y escribió en su totalidad en 1889.

Para esta colección escribió una "Nota biográfica" Gaspar Mortillaro. En este prefacio se muestra Mortillaro tan devoto y admirador de Marí como todos los que sobre esta excelsa figura han escrito. En esta "Nota biográfica" se han deslizado varios errores. Rectifico los siguientes: Martí dejó inéditos sus Versos libres; que yo sepa no visitó a Colombia; Amistad funesta no es pieza teatral sino un esbozo de novela escrito muy a la carrera y de compromiso para ayudar a una amiga leal; no fué en 1893 sino en 1895 cuando "combatió la dominación española en Cuba con las armas en la mano".

A las tres antologías mencionadas hay que agregar otra traducida al portugués y publicada en Río de Janeiro en el presente año. Mas de ésta se hablará en la sección correspondiente de esta Revista.

\title{
DOS VALIOSOS LIBROS ARGENTINOS
}

La Comisión Argentina de Cooperación Intelectual que preside el Dr. Carlos Ibarguren, y de la cual es secretario entusiasta el distinguido escritor argentino Antonio Aita, ha publicado recientemente dos valiosos libros que deseo señalar a la atención de los lectores de la Revista Iberoamericana. La indole y el mérito de estos volúmenes es desigual; pero los dos merecen la detenida lectura y meditación de cuantos se preocupan por nuestra cultura. Doy cuenta de ellos por el orden cronológico en que aparecieron. Con la publicación de estos dos tomos, la Comisión Argentina de Cooperación Intelectual ha realizado una labor de alta cultura y de positivo beneficio para las letras de América. Confiemos en que la Comisión continuará tan plausible esfuerzo.

Europa-América Latina.-Buenos Aires, Comisión Argentina de Cooperación Intelectual, 1937. $249 \mathrm{pp}$.

Se reúnen en este tomo las deliberaciones de los intelectuales que concurrieron a la Séptima Conversación de la Organización de Cooperación Intelectual de la Sociedad de las Naciones que tuvo lugar del 11 al 16 de septiembre de 1936. En dicho año se congregó en la urbe platense el XIV Congreso de la Federación Internacional de P. E.N. Clubs y el 
secretario del P.E. N. Club argentino, el señor Antonio Aita, tuvo la feliz idea de proponer al Instituto Internacional de Cooperación Intelectual de la Sociedad de las Naciones, la celebración en Buenos Aires de la Séptima Conversación de este organismo para aprovechar la presencia en aquella ciudad de los concurrentes al congreso de los P. E. N. Clubs. A estos actos asistieron muchos de los intelectuales más ilustres de América y Europa, que por primera vez en la historia de la civilización occidental se reunian para deliberar sobre las relaciones culturales que unen a los dos continentes, explorar sus afinidades y divergencias $y$, a la vez, señalar rumbos nuevos para el futuro. Asistieron a este cónclave y participaron en sus debates, las siguientes personalidades de gran relieve: Alcides Arguedas, Enrique Diez-Canedo, Georges Duhamel, W. J. Entwistle, Joan Estelrich, Fidelino de Figueiredo, Pedro Henríquez Ureña, Carlos Ibarguren, Conde Keyserling (no asistió, pero envió una interesantísima comunicación), Emil Ludwig, Jacques Maritain, R. H. Mottram, Afranio Peixoto, Louis Pierard, Alfonso Reyes, Carlos Reyles, Jules Romains, Francisco Romero, Baldomero Sanín Cano, Juan B. Terán, G. Ungaretti y Stefan Zweig. Presidió el "entretien" por elección unánime de los concurrentes, el ilustre ensayista y crítico colombiano don Baldomero Sanín Cano, una de las mentes más lúcidas y más trabajadas de nuestra América.

Los señores Díez-Canedo, Henríquez Ureña, Ibarguren, Keyserling, Peixoto, Pierard, Reyles, Romero, Sanín Cano y Terán, sometieron sendas comunicaciones previas, que tras un acucioso análisis de las mismas realizado por los señores Estelrich y Henríquez Ureña, sirvieron de base a las deliberaciones de los asistentes al "entretien". La dilucidación de las conclusiones presentadas por los diez comunicantes requeriría mucho más espacio del que aquí dispongo. Desde el primer instante, y ya en estas diez comunicaciones, se notó cierta divergencia entre los delegados europeos y los de la América ibera. Así, los señores Henríquez Ureña, Ibarguren, Reyles, Romero, Sanín Cano y Terán sostuvieron con más o menos énfasis en sus respectivas comunicaciones la progresiva independencia y originalidad de la cultura americana frente a la de Europa. A $\tan$ autorizadas voces se sumaron después otras como la de Alfonso Reyes, que abunda en análogo parecer. Entre los delegados europeos, el mejor conocedor de la cultura americana era Díez-Canedo, quien sostuvo la unidad fundamental de las culturas europea y latinoamericana. Sus colegas europeos, menos familiarizados con el movimiento intelectual de América, empezaron prudentemente por una petición de datos que puso sobre el tapete el tema fundamental de la conversación: la originalidad y las características esenciales de nuestra cultura.

En torno a este tema y sus derivados giraron casi todas las deliberaciones. Los delegados americanos últimamente citados sostuvieron - sin demostrarla- desde el primer instante la premisa de que la cultura americana se distancia cada día más de Europa y como secuela va adquiriendo un matiz propio y un espíritu original, autóctono, que la distin- 
gue de la europea. Algunos de ellos apuntaron también la desilusión de América frente al desastre de la guerra mundial, desilusión que para muchos se ha traducido en un profundo escepticismo. Europa ya no es nuestro guía infalible, dicen, ni puede darnos pautas salvadoras. De rechazo, esto ha propiciado el desarrollo de la cultura vernacular con caracteres e ideales propios.

Los delegados europeos pidieron reiteradamente a sus colegas de América que demostraran este postulado, que concretaran en definiciones precisas el contenido de la originalidad que sostenían. No hubo en esta actitud espíritu de negación, sino más bien deseo genuino de sẹr informados. Tras mucho debatir el punto y de ofrecer algunos casos concretos por vía de ejemplo, los delegados americanos no pudieron o no quisieron satisfacer la curiosidad sin malicia de los colegas europeos. El tema es de suyo reacio a las definiciones concretas y precisas y hubo de abandonarse por indefinible. Si las afirmaciones apriorísticas de los que sostuvieron el paulatino desprendimiento de la cultura americana -Alfonso Reyes prefiere el término "inteligencia americana"- convencieron o no a los representantes europeos, es cosa que no se trasluce en las páginas de este volumen. Pero sospecho que no debieron quedar muy persuadidos.

El otro tema central objeto de larga deliberación fué el de la posibilidad de un renacimiento humanista. El nuevo humanismo y las bases sobre las cuales debía cimentarse la cultura occidental ocupó el resto de la "conversación". Como el tema anterior, éste quedó sub judice y sin solución concreta. El será objeto de un segundo volumen que pronto publicará la Comisión Argentina de Cooperación Intelectual.

Pero si los resultados prácticos de estas deliberaciones fueron de muy escasa significación, en cambio, este tête-a-tête intelectual entre algunas de las mentalidades más representativas de ambos continentes, contribuyó en grado no escaso a esclarecer algunos puntos poco explorados y sirvió para interesar a los colegas europeos en nuestra cultura. En un punto esencial coincidieron los delegados americanos: en la necesidad de reconocerle beligerancia y universalidad a nuestra cultura. En grado variable, todos sostuvieron también su madurez inicial y su progresiva originalidad. Si no demostraron este último postulado, por lo menos hicieron esta afirmación unánime de independencia y pubertad espirituales, y ya esto es algo. El debate, pues, resultó en alto grado provechoso e interesante.

Mas leyendo ahora este diálogo platónico mientras Europa entera asiste a la mayor catástrofe que registra la historia, el lector no puede menos de llegar a conclusiones un tanto melancólicas y desconsoladoras. Lo primero que se echa de ver es la escasa trascendencia de estos ilustres cónclaves en los rumbos de la humanidad. En las deliberaciones del "entretien" de Buenos Aires casi no se le reconoció beligerancia al factor económico, que apenas se mencionó, y lo mismo al factor social. Todavía no nos damos cuenta de que la humanidad, hoy como en la edad de la 
horda y el clan, se mueve por impulsos egoístas, y que el factor económico pesa más en los destinos de la cultura que todos los sistemas filosóficos hasta ahora ideados. Este divorcio entre las elucubraciones intelectuales de los filósofos y la trágica realidad económica y social que vivimos es precisamente lo que provoca el pesimismo del lector. Este divorcio fué denunciado por Emil Ludwig al concluir la última sesión. Refiriéndose al inminente peligro de la guetra en Europa y a sus terribles consecuencias para la cultura occidental, dijo Ludwig: "He visto que ustedes, en cierta manera, querrían aislarse del mundo exterior para que nada viniera a distraer la atención del filósofo que se ocupa de la historia de la razón". Fué una discreta llamada a la realidad, de la cual todos habían pugnado por evadirse.

El paisaje y el alma argentina.-Buenos Aires, Comisión Argentina de Cooperación Intelectual, 1938. 492 pp.

Es ésta un valiosa selección en prosa realizada por los señores Ibarguren, Aita y Pedro Juan Vignale. Entre la copiosa literatura paisajista, narrativa y costumbrista argentina, han espigado los antologistas veintiocho cuadros descriptivos del ambiente, las costumbres, el paisaje, la naturaleza y las leyendas argentinas, que dan idea cabal del alma y la vida en aquella república. Inician la crestomatía unas páginas arrancadas al Facundo, en las que Sarmiento describe el ambiente físico y moral de la pampa, así como su espíritu retardatario. En el resto del libro, los zuentos se entremezclan con las descripciones paisajistas o con las narraciones costumbristas.

Es de notar la importancia concedida en esta antología a la literatura de tipo gauchesco - una prueba más de la trascendencia que este tipo social tuvo en la organización nacional y sigue teniendo en la literatura y el arte. Más de la mitad del volumen está consagrado a temas gauchescos.

Puede afirmarse que la mayoría de los principales novelistas y cuentistas argentinos están aquí representados. También se incluyen muchos de los mejores escritores descriptivos y paisajistas como Lucio V. Mansilla, Guillermo Enrique Hudson, Ricardo Rojas, Carlos Ibarguren, Joaquín V. González, etc. Es ésta, por consiguiente, una excelente síntesis de aquella parte de la literatura argentina más directamente relacionada con el paisaje y el espíritu argentinos.

La antología va precedida de un enjundioso prólogo de Carlos Ibarguren y seguida de una bibliografía selecta de cada uno de los autores incluídos, la cual acrece el mérito informativo del libro.

Otra utilisima iniciativa de la Comisión Argentina de Cooperación Intelectual, es la publicación del Boletín Bibliográfico Argentino, en el 